\title{
FORGIVENESS THERAPY FOR SALEMBA PENITENTIARY INMATES
}

\author{
Hifizah Nur \\ Universitas Mercu Buana Jakarta, Indonesia.
}

\begin{abstract}
Forgiveness is defined as "motivation to reduce the desire to avoid and take revenge on someone who has hurt or offended him or her, and to increase the meeting between two parties to solve a problem if it is considered safe, wise, or possible to do" (Worthington et al., 2000 : 229). Salemba Prison inmates are prisoners or Penitentiary Guards, or they can be still in the judicial process and has not been found guilty or not by the judge. They are serving a sentence for a crime they have committed. From the data in various media, a person commits a crime caused by various things, one of which is because of revenge. This revenge comes from anger that is fostered continuously and encouraged someone to do violence. Therefore, a positive effort is needed to be able to lead this anger and revenge, become units of behavior through the process of forgiveness. Therefore, forgiveness therapy psycho-education is an important thing that needs to be done to Salemba prison prisoners.
\end{abstract}

Key words: Forgiveness, Prison Inmates, Psycho-Education

\section{Introduction}

Penitentiary (LAPAS) is a place to accommodate the training activities for prisoners, both physical and spiritual guidance so that they can live a normal life when they go back to the community. There are a view types of Penitentiary services divided by age and sex factors, they are (1) Public Penitentiary, the place to accommodate male convicts who are over 25 years old (2) Special Penitentiary which are a. Women's Penitentiary to accommodate female convicts who are over 21 years old or are married. b. Youth Penitentiary to accommodate young prisoners aged 18-25 years. c. Penitentiary for Children consists of Penitentiary for Boys and Penitentiary for Girls. On the other hand, there are also classification of Penitentiaries based on capacity, domicile and work activities, namely (1) Class I penitentiary Located in the Capital of the Province with a capacity of more than 500 people (2) Class II A penitentiary located in municipality with a capacity of 250-500 people (3) Class II B penitentiary Located in district level, the capacity is less than 250 people (Apriansyah, 2016).

Salemba penitentiary inmates are prisoners, or they can be still in the judicial process and has not been found guilty or not by the judge. They are serving a sentence for a crime they have committed. From the data in various media, a person commits a crime caused by various things, one of which is because of revenge. The number of crime victims who actually put revenge into practice is unknown. From the result of one study, victims of ethnically motivated violence, between $41 \%$ and $46 \%$ reported strong feelings of revenge (Cardozo, et al., in Orth, Montada \& Maercker, 2006). The problem that generally occurs in prison residents is the difficulty to make peace with their past. Anger that has accumulated makes their lives difficult and ends up in penitentiary class II A Salemba. According to Agnew and other theorist, chronic strain or anger may distort the individual's attitudes, expand the "regulative rules" associated with aggressive behavior, and increase the perceived legitimacy of a violent response (Brezina, 2010).

A positive effort is needed to be able to lead this anger and revenge, become units of behavior through the process of forgiveness. Therefore, forgiveness therapy psycho-education is an important thing that needs to be done to Salemba penitentiary inmates.

\section{Theoritical Review}

Everyone has ever done wrong both to themselves and to others. One of the things that difficult to do to correct these mistakes is the ability to forgive mistakes (forgiveness) that have been done. Forgiveness is a behavior that is very important to support one's mental and physical health (Toussaint et al., 2001). In a study conducted by Lawler-Row and Piferi (2006), it was found that forgiving behavior of others is closely related to health, and behavior that cannot forgive is closely related to chronic stress, whose effects on physical health will be felt after years later.

Forgiveness is defined as "motivation to reduce the desire to avoid and retaliate against someone who has hurt or offended someone, and to increase meetings between two parties to resolve a problem if it is 
considered safe, wise, or possible to do" (Worthington et al. 2000: 229). In another definition, forgiveness is "a willingness to renounce the right to hate, give negative judgment, and indifferent behavior towards people who have hurt us unjustly, while cultivating the nature of compassion, generosity, and even love for that person" (Enright et al. 1998: 46-47). From this definition it can be concluded that forgiveness is an attempt by someone to reduce or even eliminate hate and want to repay the wrongdoing that he gets from others, while trying to forgive, increase compassion, be generous to that person.

Further explanation of this forgiving behavior are; First, not forgiving involves a mindset that might be sorry, vengeful, hostile, bitter, annoyed, angry, afraid of future danger, and depressed. Second, unforgiving behavior is hypothesized to be directly related to the amount of injustice experienced (called the inequality gap, by Exline et al. 2003). Third, forgiveness means reducing forgiveness. Fourth, forgiveness is a process and not an event. There is little agreement about the sequence, mechanism, key components, and changes in the process. Fifth, the experience of forgiveness can be distinguished from its interpersonal context. Like Baumeister et al. (1998) observed that in grudge theory, a person can internally forgive and not express it or can express forgiveness but not experience it internally. Sixth, forgiving strangers or unwanted people or expecting ongoing contact is fundamentally different from forgiving a loved one. Seventh, making a decision to change one's behavior can be a form of sincere and permanent forgiveness, but that decision must be distinguished from emotional forgiveness. Emotional forgiveness is likely to be more related to the health element because of its strong relationship to overcome negative influences and stress reactions by developing positive influences. Eighth, most would agree that (a) explicit forgiveness has the potential to cause emotional and eventual change in behavior, whereas (b) emotional forgiveness, by definition involves changes in emotions, motivation, cognition, and ultimately behavior.

\section{Implementation Method}

Community service of forgiveness therapy is conducted in prison class II A Salemba and was held at 2:00 p.m. and ended at 4:00 p.m. 30 Participants are selected based on the purpose of community service, that is, those who need forgiveness therapy according to the judgment of the head of human resources development of the prison. Participants who were mostly aged between 18-35 years indicated that they were still in their productive age (early adulthood phase) and they still had the opportunity to improve themselves and their future.

This service consists of several stages: (1) explanation of the importance of forgiveness, (2) Workshop of forgiveness therapy, and (3) Filling evaluation questionnaire.

Forgiveness therapy begins by providing an explanation of the importance of forgiveness, both for physical and mental health of the person. After that, it was described the consequences of anger that is buried, both in the short term and for the long term, which way manifest in the form of depression, trauma, phobia, insomnia, addiction, hysteria (blind, mute, deaf, paralyzed), obsessive-compulsive, stress, anxiety, worry, panic, heart disease, cancer and endless revenge. So, forgiving is an important activity for one self, and has nothing to do with other people.

\section{Picture 1. Explanation of The Importance of Forgiveness}

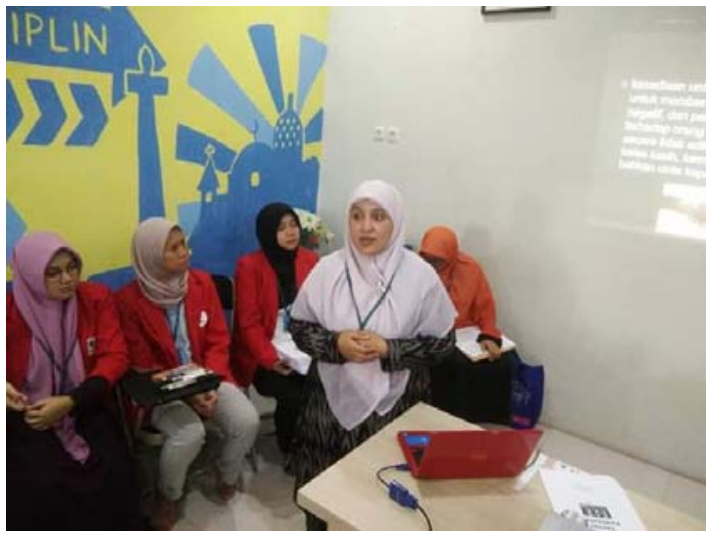

In the next stage, participants were asked to look back on their past, open up the painful parts of their lives and invite them to make peace with these dark parts. Therapeutic tools that are used are tools compiled by Drs. Asep Haerul Gani, Psychologist, from stage one to stage seven of the 13 stages in forgiveness therapy. Participants were asked to fill in a therapeutic guide consisting of, (1) the lifeline of the traumatic event, (2) the traumatic level scale of the event, (3) the sickness in the self which contains the loss of the person who buried 
anger towards other persons, (4) the narrator of the bitter story that contains the loss of people who always tell the difficulties and anger they have, (5) Alarm to forgive, (6) Ethics of forgiveness and (7) the decision to forgive.

Picture 2. Workshop of forgiveness therapy

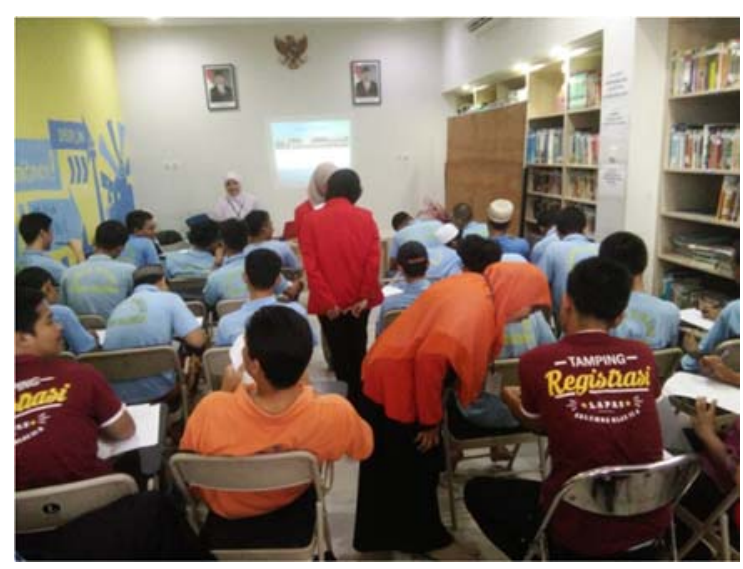

After undergoing seven stages of forgiveness therapy, participants were asked to fill out a questionnaire to evaluate the activities carried out that day. The following is a summary of counseling evaluations presented in tabular form;

Picture 3. Evaluation Before and After Workshop

\begin{tabular}{|c|l|l|}
\hline No & \multicolumn{1}{|c|}{ Before Workshop } & \multicolumn{1}{|c|}{ After Workshop } \\
\hline 1. & $\begin{array}{l}\text { Don't know that anger and revenge hurt } \\
\text { themself }\end{array}$ & $\begin{array}{l}\text { Understand that burying anger to oneself and others causes } \\
\text { physical and mental illness }\end{array}$ \\
\hline 2. & Don't know how to forgive & $\begin{array}{l}\text { Can follow the process of forgiveness therapy step by step, } \\
\text { until making decision to be able to forgive }\end{array}$ \\
\hline
\end{tabular}

Picture 4. Photo session with Penitentiary Officers

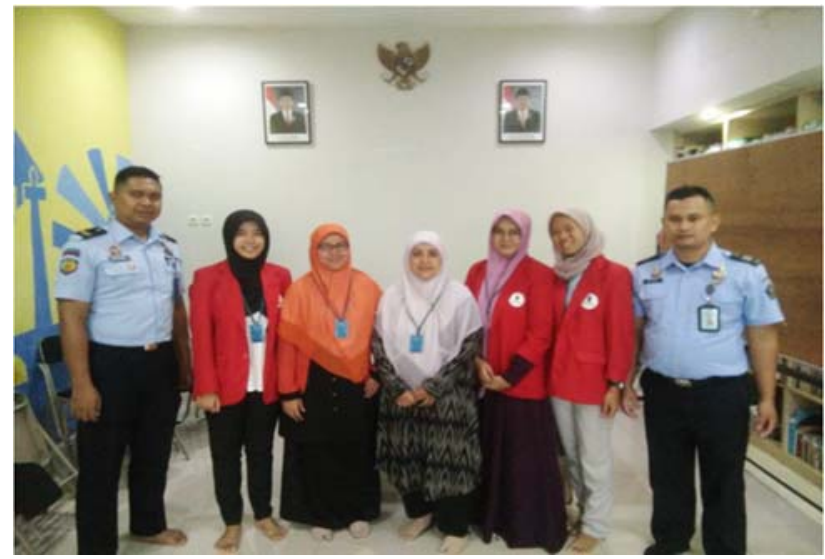

\section{Conclusion}

From the results of the implementation of the community service program to penitentiary class II A Salemba residents can be concluded as follows; (1) participants generally feel interested and enthusiastic about the activities carried out by seeing their diligence in filling the stages of therapeutic tools. (2) Their comments when filling therapeutic tools that sometimes talk about their bitter lives, can be concluded that the material is sufficient to suit their needs. (3) The results of the questionnaire at the end of the program showed that most of them felt this program was useful and they would try to forgive. To improve the quality of community service programs, it can be suggested that deeper of forgiveness therapy can be carried out further on other occasions with a smaller number of participants. 
Brezina, Timothy (2010). Anger, Attitudes, and Aggressive Behavior: Exploring the Affective and Cognitive Foundations of Angry Aggression. Journal of Contemporary Criminal Justice 26(2) 186 -203 (C) 2010 SAGE Publications Reprints and permission: http://www. sagepub.com/journalsPermissions.nav DOI: 10.1177/1043986209359849 http://ccj.sagepub.com

Lamb, Sharon (2006). Forgiveness, Women, and Responsibility to the Group. Journal of Human Rights, 5:45-60. Copyright Taylor \& Francis Group, LLC

Orth, Montanda \& Maercker (2006). Feelings of Revenge, Retaliation Motive, and Posttraumatic Stress Reactions in Crime Victims. Journal of Interpersonal Violence Volume 21 Number 2 February 2006 229-243 (C) 2006 Sage Publications 10.1177/0886260505282286 http://jiv.sagepub.com hosted at http://online.sagepub.com

W. Baskin, Thomas \& Slaten, Christopher D (2015). Forgiveness Therapy with Adolescents. https://www.researchgate.net/publication/282155885

Worthington, Everett L. Jr at.al (2007). Forgiveness, Health, and Well-Being: A Review of Evidence for Emotional Versus Decisional Forgiveness, Dispositional Forgivingness, and Reduced Unforgiveness. Springer Science+Business Media, LLC 